\title{
Gas hydrate saturation from seismic data constrained by log data in the Krishna-Godavari Basin
}

\author{
Uma Shankar ${ }^{1}$
}

Received: 30 September 2014 / Accepted: 4 May 2015/Published online: 26 May 2015

(C) The Author(s) 2015. This article is published with open access at Springerlink.com

\begin{abstract}
A strong bottom simulating reflector (BSR) was observed along seismic line transect across site NGHP01-05 having characteristic reverse polarity with respect to seafloor, cross-cutting of dipping strata, and high reflectivity below the BSR. The observed BSR depth along seismic profile varies from $\sim 100$ to $\sim 125$ mbsf. Gas hydrate was recovered during coring and drilling at this site during National Gas Hydrate Drilling Expedition-01 of India. Recovered pressure cores at discrete depths within gas hydrate stability zone from site NGHP-01-05 shows $\sim 0.6-9.4 \%$ pore volume of methane hydrate. Gas hydrate saturation was estimated along seismic profile constrained by observed velocity and density log to introduce modelbased acoustic impedance inversion. It was observed that each stacked trace amplitude converted to acoustic log as a product of velocity and density. During the impedance inversion process inverted velocity log was observed at each and every trace act as an individual log. Gas hydrate saturation was estimated from inverted velocity coupled with effective medium rock physics modeling. The estimated gas hydrate saturation from the post-stack acoustic impedance inversion velocity along $2 \mathrm{D}$ seismic profile varies up to $15-20 \%$ of the pore space. The gas hydrate saturation estimated from electrical resistivity log and core data shows maximum $20 \%$ pore spaces saturated with gas hydrate from anisotropic modeling, which is comparable to gas hydrate saturation along seismic profile estimated from inverted velocity constrained by logs.
\end{abstract}

Uma Shankar

umashankar_ngri@yahoo.com

1 CSIR-National Geophysical Research Institute, Hyderabad 500007, India
Keywords Gas hydrate · BSR · Well logs - Resistivity · Sonic P-wave velocity - Acoustic impedance inversion . Saturation

\section{Introduction}

Natural gas hydrates look ice-like crystalline solid structure that form from a combination of water and hydrocarbon gases (mainly methane). Gas hydrate formed at low temperature and highly compressed environment in the continental margins and permafrost region worldwide. Gas hydrate considered as a potential energy resource for the future. Gas hydrate is remotely detected by active seismic method on seismic section by a reflector called bottom simulating reflector (BSR). The BSR has reversed polarity with respect to seafloor and significant characteristic of cross-cutting of dipping reflectors. Presence of gas hydrate increases the strength of the sediment so that velocity reversal is evident at the BSR. Dissociation of gas hydrate at large scale may cause geological hazard in turn global climate change (Dickens et al. 1995; Paull et al. 2000; Nixon and Grozic 2007). The depth range within which gas hydrate can exist is called the gas hydrate stability zone (GHSZ) and is governed primarily by the water temperature at the seafloor, geothermal gradient, water depth, gas composition, and pore water salinity. A considerable amount of gas hydrate is thought to be present in continental margin sediment worldwide (Kvenvolden 1993; Milkov 2004; Wallmann et al. 2012; Pinero et al. 2013). Identification and quantification of gas hydrate and free gas is, therefore, important for evaluating its role on potential future energy resources and understanding geo-hazards on continental margins. 
Fig. 1 Inset shows the study area location. Bathymetric map of the Krishna-Godavari (KG) Basin targeted during Indian National Gas Hydrate Drilling Expedition-01. The small, filled red circle shows the NGHP-0105 studied in this paper. The location of the 2D multi-channel seismic line is shown with bold blue line

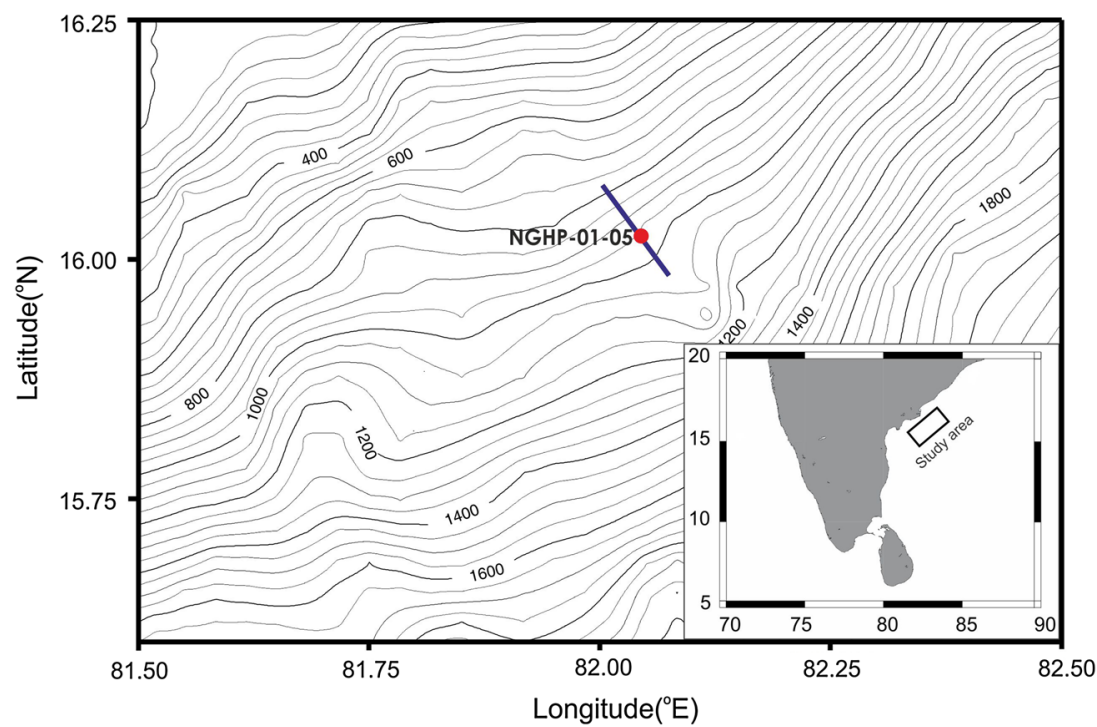

The Krishna-Godavari (KG) basin is a sedimentary basin situated on the eastern continental margin of India (Fig. 1). It is characterized by up to $5 \mathrm{~km}$ of sediments (Rao 2001). Bottom simulating reflections (BSRs) in multichannel seismic (MCS) data are the prime indicator of the presence of gas hydrate in the KG basin (Collett et al. 2008; Ramana et al. 2009; Shankar and Riedel 2010; Riedel et al. 2011; Riedel and Shankar 2012). In AprilAugust of 2006, 39 holes at 21 sites were drilled by the Director General of Hydrocarbon (DGH), Noida, India, using the research drill ship JOIDES Resolution (Collett et al. 2008). The objective of the program was to collect sediment cores and obtain well logs in an area where there was substantial seismic evidence for the occurrence of gas hydrate. National gas hydrate program (NGHP) Expedition-01 targeted the KG basin slope region at water depths of 900-1300 m. The coring and drilling sites are shown in Fig. 1. The KG basin site has a prominent regional BSR and lithologies are dominated by clay (90-95\%) and a small amount of silt (5-10\%), and sand at almost all sites (Collett et al. 2008).

Site NGHP-01-05 was drilled at water depth $\sim 945 \mathrm{~m}$ and a BSR at depth $\sim 115$ along seismic line crossing this site was observed. Logging-while-drilling (LWD) and wireline were run at site NGHP-01-05. At site NGHP-0105, five holes (NGHP-01-05A-NGHP-01-05E) around 10-12 m apart were drilled and cored. Holes NGHP-01-5A and NGHP-01-05B were drilled for LWD. Holes NGHP01-05C and NGHP-01-05D were cored up to $\sim 200 \mathrm{mbsf}$ and hole NGHP-01-05E was drilled for wireline and vertical seismic profiling (VSP) data were recorded up to $\sim 200$ mbsf. Two successful pressure cores were recovered at 79.3 and $87 \mathrm{mbsf}$ in hole NGHP-01-05C and four pressure core recovered at $76.9,84.9,114.9$, and $124.9 \mathrm{mbsf}$ in hole NGHP-01-05D. The wireline sonic
P-wave velocity, density, porosity, electrical resistivity logs, and core data are used for this study.

In the KG Basin gas hydrate in clay dominated sediment distributed in the form of layers, nodules, fracture-filling and pore filling was recovered from various well (Collett et al. 2008). Resistivity and velocitylogs are commonly used to estimate gas hydrate saturations in gas hydrate bearing sediments. Uniform gas hydrate distribution in the sediment pore space considered isotropic medium and the physical properties such as velocity and resistivity are isotropic (Lee and Collett 2012). If gas hydrate formed in fractures, commonly in unconsolidated clay-bearing sediment, the physical properties are anisotropic and isotropic rock physics modeling yields higher estimate of gas hydrate saturation (Lee and Collett 2009; Lee and Collett 2012; Cook and Goldberg 2008; Cook et al. 2014). Fracture fill gas hydrate in clay dominated sediment was observed at site NGHP-01-05 logs (Collett et al. 2008; Cook et al. 2014). In the fracture reservoir, very high resistivity and high velocity were observed.

The presence of gas hydrate in marine sediments increases the compressional wave velocity and decreases velocity due to presence of free gas or water without much effect on the density. Therefore, product of density and velocity produces acoustic impedance, which is much higher for gas hydrate compared to the presence of free gas or water in the sediments below BSR. Hence, acoustic impedance can be used for identification and velocity used for the quantification of gas hydrate. The KG Basin is one of the major gas hydrate reserves established after NGHP Expedition-01 in the eastern continental margin of India, which has complex geology, making conventional seismic data interpretation a challenging task for understanding the reservoir properties. Seismic inversion technique has become important tool to integrate seismic and well log data 
for gas hydrate reservoir characterization and to extract additional information from seismic data. In this study post-stack seismic inversion was performed to transform seismic data into physical properties of the sediment constrained by acoustic velocity and density log for the estimation of aerial and vertical extent of gas hydrate saturation along seismic profile in the $\mathrm{KG}$ Basin from anisotropic modeling approach for the accurate estimate of gas hydrate saturation from resistivity and velocity data (Lee and Collett 2009).

The objective of this study was to estimate spatial distribution of gas hydrate saturation along 2D seismic profile constraining well log measurements. Well-log-information provides a direct and discrete measurement to obtain gas hydrate saturation by measuring $\mathrm{P}$-wave velocity, porosity and density of gas hydrate-bearing sediments from isotropic and anisotropic modeling approach. However, the challenge is to extrapolate the well-log information away from the borehole along seismic profile to achieve a complete assessment of a gas hydrate deposit. In this paper well-log techniques were used to quantify gas hydrate concentrations and then acoustic impedance inversion on 2D post-stack seismic data was applied to infer regional gas hydrate assessment.

\section{Seismic and well log data and their correlation}

In this study multi-channel seismic data, acquired by the Directorate General of Hydrocarbons (DGH) (Collett et al. 2008), were used. The complete data set was also previously used for defining geophysical drilling targets and site selection for the NGHP Expedition-01. Strong BSR was observed along seismic line (Fig. 2). The seismic profile total offset is $31,175 \mathrm{~m}$ and common depth point (CDP) interval is $25 \mathrm{~m}$ with total number of CDP 1247. Data processing carried out by DGH included basic band-pass

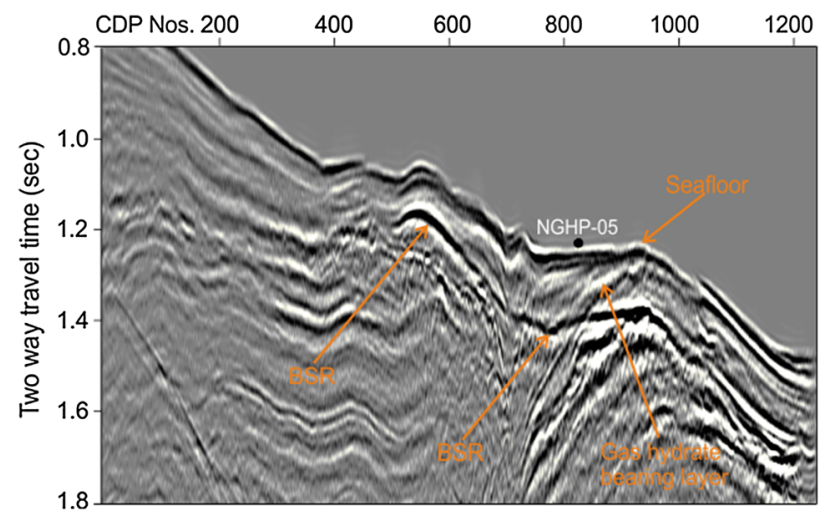

Fig. 2 Resistivity logs are overlain on the seismic section crossing to NGHP-01-05 site. A strong BSR is observed on the seismic section underlain by high reflectivity filtering, common-mid-point sorting, static corrections, true amplitude recovery, velocity analysis, stacking, and timemigration. The bottom-simulating reflector (BSR) observed in the vicinity of NGHP-01-05 indicates that the base of the gas hydrate stability zone is at a depth of $115 \mathrm{mbsf}$ at this site. Figure 2 shows the seismic profile with the resistivity $\log$ superimposed. The high-resistivity anomalies are correlated with a high-amplitude arrival in the seismic data at $1.3 \mathrm{~s}$, which might be a gas hydrate-bearing layer within the gas hydrate stability zone. The frequency content of the 2D seismic data ranges from 10 to $80 \mathrm{~Hz}$ and dominant frequency around $40 \mathrm{~Hz}$, resulting in vertical resolution of $\sim 10 \mathrm{~m}$ above the BSR.

Figure 3 shows the suite of logs at site NGHP-01-05. The depths relative to seafloor were fixed for all of the LWD logs by identifying the step change in the GeoVISION gamma ray log at the seafloor. For example, in hole NGHP-01-05A and 05B gamma ray logging picked for seafloor was $7 \mathrm{~m}$ shallower and $2.7 \mathrm{~m}$ deeper, respectively, than the initial depth estimated by driller (Collett et al. 2008). The gamma ray (GR) log shows an increasing trend up to just above BSR. Two relatively high-resistivity zones (70-79 and 81-93 m) are indicated by the resistivity logs in Fig. 3. The P-wave log shows high velocities above the BSR from 80 to $115 \mathrm{~m}$ and low velocity $(<1.5 \mathrm{~km} / \mathrm{s})$ below the BSR. The S-wave log was not recorded properly and is not used for gas hydrate saturation estimate. The density and the neutron porosity logs appear to be reliable throughout the logging depth. Density and porosity measurements on core samples are superimposed on the corresponding logs and follow similar trends (Fig. 3). The shallow zone of the log above $20 \mathrm{mbsf}$ cannot be used because the caliper log shows a much enlarged hole near the seafloor. The resistivity log suggests two zones of high hydrate concentration at $\sim 70-79$ and $\sim 81-93$ mbsf. The velocity $\log$ suggests that the presence of free gas below the BSR. Above the BSR, the velocity structure suggests the presence of gas hydrate in distinct layer from $\sim 82$ to 115 mbsf. Examination of the coring results did not yield any insights into the region for this apparent mismatch between the two distinct data sets.

Well-to-seismic correlation provides an efficient way to establish hydrate events on seismic data and for the calibration of a hydrate estimation using an appropriate model. Well-based, zero-offset synthetic seismogram was created and compared with the post-stack seismic traces at the well location (Fig. 4). For the synthetics, the impedance was calculated from the product of P-wave velocity and bulk density logs. Wavelet was extracted from the seismic data near the well to create the synthetic seismic traces. The tie between the synthetic and the seismic data at the well location is reasonably good in the zone of interest ( 1380-1480 ms) (Fig. 4). The characteristic peak at the 


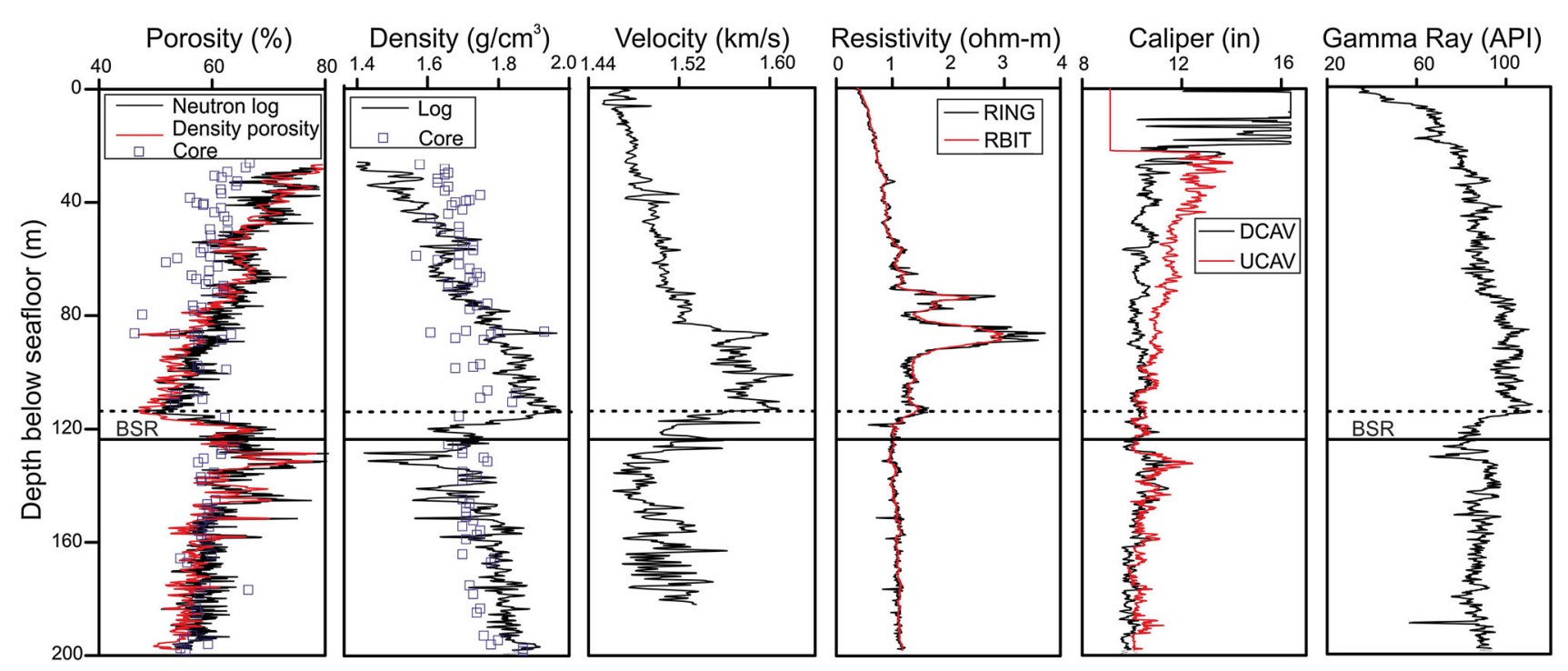

Fig. 3 Suite of logs from site NGHP-01-05, including neutron porosity (NPHI), bulk density (RHOB), sonic P-wave velocity, electrical resistivity (RING, RBIT), caliper (DCAV, UCAV), and gamma ray (GR). Blue squares show porosity and density from core samples superimposed on the corresponding log curve. The seismically inferred BSR is highlighted by the solid black line
Fig. 4 Well-to-seismic tie for stack 2D seismic data and correlation of the synthetic and the stacked seismic data at well NGHP-01-05. Blue traces represent synthetic seismograms, red traces represent the extracted trace from the seismic volume at the well location, and black traces shows the nine traces around the well location

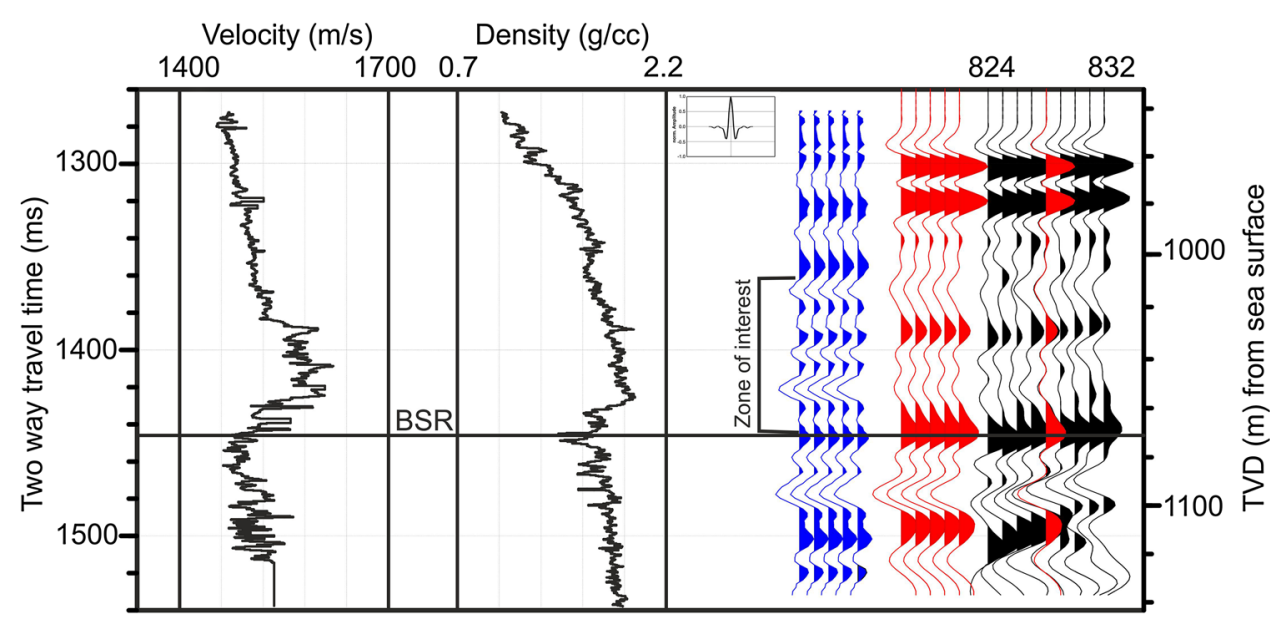

BSR ( $\sim 1450 \mathrm{~ms})$ as shown in Fig. 4 is reasonably well replicated in the synthetic and seismic data.

\section{Materials and methods}

Estimating gas hydrate saturation from P-wave velocity data using an effective medium approach requires knowledge of the elastic properties of the background rocks and a rock physics model that accounts for the effect of gas hydrate on the host rocks. Estimated gas hydrate saturations can vary widely depending on the model used (Pearson et al. 1983; Mathews 1986; Guerin et al. 1999; Hyndman et al. 1999; Collett et al. 1984, 1999; Collett 2001; Kleinberg et al. 2003; Lee and Collett 2008, 2009). Gas hydrate can be modeled either as part of the pore fluid (gas hydrate in-pore) or as part of the load-bearing sediment matrix (gas hydrate in-frame) (Helgerud et al. 1999). The gas hydrate in-pore model assumes that the gas hydrate floats in the sediment pore space and does not add stiffness to the sediment frame. As a consequence, the sediment $\mathrm{S}$-(shear) wave velocity is nearly unaffected by the occurrence of gas hydrate. For the gas hydrate in-frame model, grains of gas hydrate are included as part of the sediment frame, stiffening the sediment. For this model, the sediment $\mathrm{S}$-wave velocity is slightly increased by gas hydrate but much less than for a model in which gas hydrate actually cements the grain contacts (e.g., Dvorkin and Nur 1993). Both the gas hydrate in-pore and in-frame models predict an increase in $\mathrm{P}$-wave velocity with increased gas 
hydrate concentration (slightly more for the gas hydrate inframe model). The gas hydrate in-frame model is most accurate in high-porosity, clay-rich marine sediments (Helgerud et al. 1999).

Gas hydrate present in sediment fracture fill can be modeled with anisotropic modeling as a layered media composed of two components (White 1965; Lee 2009). The first component is fracture fully filled with gas hydrate with its properties given by $\mathrm{P}$ and $\mathrm{S}$-wave velocity and density. The second component is isotropic sediment characterized by another set of $\mathrm{P}$ and $\mathrm{S}$-wave velocity and density. The layered media and their velocities are estimated from White (1965) and Lee and Collett (2012).

Electrical resistivity is commonly used logs for estimating gas hydrate saturation. Gas hydrate-bearing sediments exhibit relatively high electrical resistivity in comparison to water-saturated units. The relation between rock and pore fluid resistivity has been studied in numerous laboratory and field experiments. Many subsequent studies using borehole log data, core data, and laboratory measurements have confirmed that an exponential relation is good approximation for relating resistivity to porosity (Jackson et al. 1978; Swanson 1979; Hilfer 1991; Ioannidis et al. 1997).

The electrical resistivity of water-saturated sediments $\left(R_{\mathrm{O}}\right)$ can be expressed using the Archie equation (Archie 1942) as given below:

$R_{\mathrm{o}}=\left(a R_{\mathrm{w}} / \phi^{m}\right)$,

where $R_{\mathrm{o}}$ is the formation resistivity of water-saturated sediment, $R_{\mathrm{w}}$ is the formation water resistivity, $a$ and $m$ are Archie constants, and $\varphi$ is the porosity. $R_{\mathrm{w}}$ was calculated using the equation of state of seawater (Fofonoff 1985) from core-derived in situ pore water property measurements. Pressure is assumed to be hydrostatic. Measured in situ temperature, pore water salinity and regional geothermal gradient at site NGHP01-05 were used to derive resistivity of formation water. Archie constants $a$ and $m$ can be determined from the cross-plot between formation factor and density porosity of water-saturated sediments by power function (Fig. 5). There is considerable scatter in the cross-plot due to the presence of gas hydrate within the gas hydrate stability zone. Equation 1 can be solved for the ratio of watersaturated sediment resistivity, and formation water resistivity gives formation factor (i.e., $\mathrm{FF}=R_{\mathrm{O}}$ l $\left.R_{\mathrm{w}}=a \varphi^{-m}\right)$. The gas hydrate saturation $\left(S_{\mathrm{h}}\right)$ in the formation from the resistivity $\log$ data can be estimated from Archie (1942) equation:

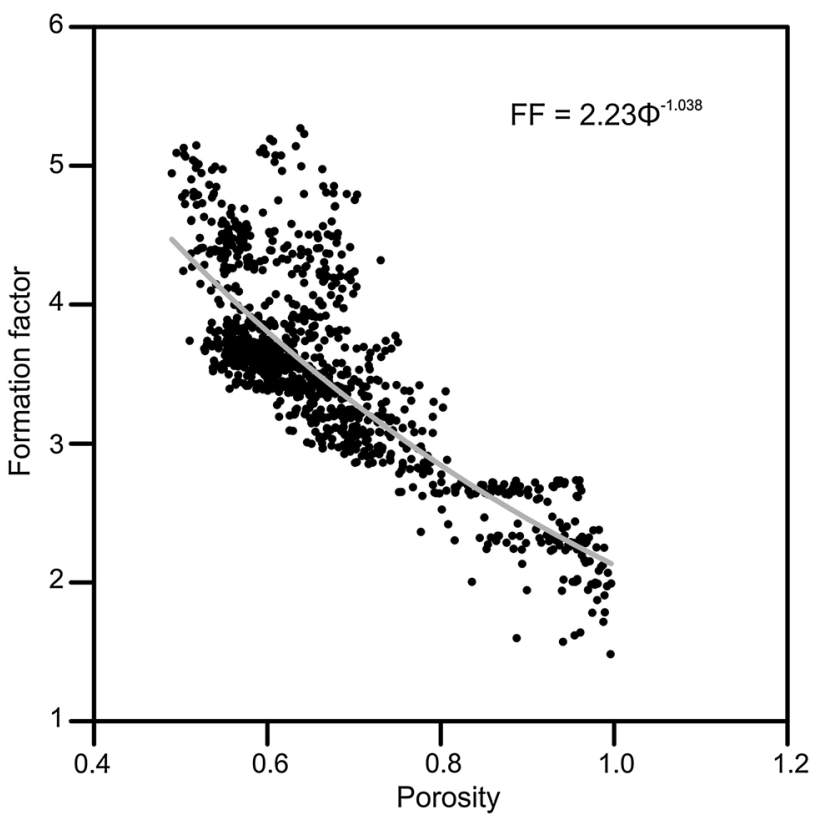

Fig. 5 Formation factor (FF) versus porosity plot for site NGHP-0105. The bold gray line is the best exponential fit, giving Archie's parameters

$S_{\mathrm{h}}=1-\left(a R_{\mathrm{w}} \phi^{-m} / R_{\mathrm{t}}\right)^{1 / n}$,

where $R_{\mathrm{t}}$ is the measured resistivity from $\log$ and $n$ is the saturation exponent. The Archie equation appropriate for water-saturated-sediments is $\mathrm{FF}=2.23 \phi^{-1.038}$ and shown as gray line in Fig. 5. The $R^{2}$ value is about $69 \%$.

A sedimentary formation is isotropic if it has same resistivity value independent of direction. If the measurement of resistivity in a given direction is greater than resistivity measurement in another two directions, this formation is termed anisotropic formation. Gas hydrate filled in fracture will be anisotropic and can be modeled from the physical properties of the fracture-filled medium and the sediments surrounding the fracture. In this exercise anisotropic resistivity modeling was performed based on Kennedy and Herrick (2004), Lee and Collett (2012) approach and physical parameters extracted from Cook and Goldberg (2008), Collett et al. (2008) and Cook et al. (2014) from study site of KG Basin.

Acoustic impedance is an important characteristic physical property of the sediment, which is a product of velocity and density. It is frequently used in seismic data interpretation for the reservoir characterization. The change in the subsurface lithology is represented by the relative change in acoustic impedance (Pendrel 2001). Acoustic impedance log is simply product of density and velocity $\log$ measured at well location. The aim of the acoustic impedance inversion along seismic profile is to 
effectively extrapolate the desired properties away from the wells by creating continuous synthetic log sections (Lindseth 1979).

Acoustic impedance computed from seismic data can be used to estimate gas hydrate saturations ( $\mathrm{Lu}$ and $\mathrm{McMe}-$ chan 2002; Dai et al. 2008; Wang et al. 2011; Riedel and Shankar 2012) using various post-stack impedance inversion methods of seismic data. In this paper the model-based inversion of Russell and Hampson (1991) was used as implemented in the Hampson Russell STRATA software package. Model-based inversion (Russell and Hampson 1991) uses a generalized linear inversion algorithm (GLI), which attempts to modify the initial model until the resulting synthetic matches the seismic trace within some acceptable limit. This method is effective when there is considerable knowledge about the geology and a reliable starting model can be created. The inversion was performed with the Hampson and Russell (HR) package. The synthetic seismogram was generated at the borehole from a statically extracted wavelet during the inversion. During the model-based inversion, the input data include the stacked seismic data, extracted wavelet, seismic horizon, and the low-frequency initial impedance model. The model-based acoustic impedance inversion flow chart is given in Fig. 6.

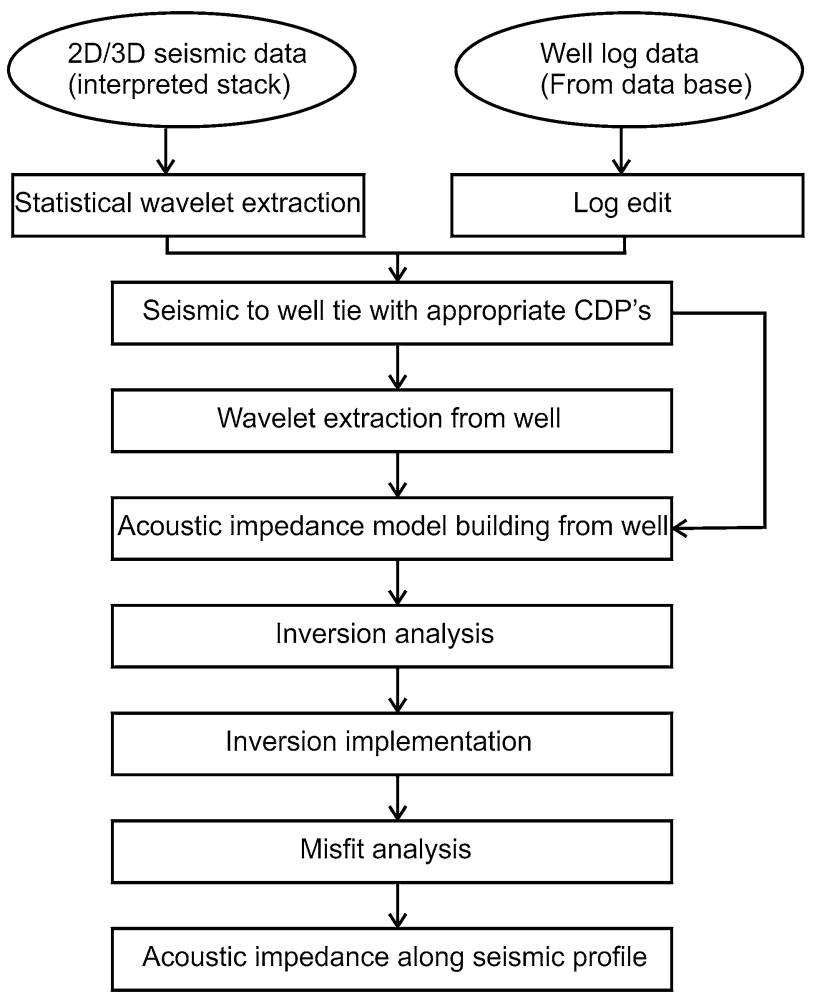

Fig. 6 Simplified flow chart for acoustic impedance analysis and acoustic impedance inversion

\section{Results and discussion}

Gas hydrate saturation from electrical resistivity log measurements using Archie's empirical equations are frequently used for the gas hydrate assessment (Lee et al. 1993; Hyndman et al. 1999; Collett 2001). P-wave velocity from forward and inverse modeling of seismic data and velocities from different logging tools (Sonic and vertical seismic profiling) can be used to estimate gas hydrate saturation using empirical relations and effective medium rock physics modeling approach depending on mod of formation of gas hydrate in the sediment (Wood 1941; Wyllie et al. 1958; Hyndman et al. 1993; Yuan et al. 1996; Dai et al. 2004, 2008; Lee and Collett 2009; Shankar and Riedel 2011). Below, the gas hydrate saturation estimates based on resistivity and acoustic velocity obtained from acoustic impedance inversion along seismic profile constrained by log data in the KG Basin are discussed.

The formation resistivity of water-saturated sediment $\left(R_{\mathrm{O}}\right)$ can be estimated from the Archie Eq. (1) after Archie's parameters $a$ and $m$ obtained from the exponential fit of the density porosity and formation factor data. Figure 7a shows the difference between the calculated in situ resistivity $\left(R_{\mathrm{O}}\right)$ and measured $\log$ resistivity $\left(R_{\mathrm{t}}\right)$ and demonstrates that the calculated $R_{\mathrm{o}}$ agrees well with the measured resistivity for most intervals with the exception of 50-100 mbsf. With the empirically estimated Archie parameters $a, m, n, R_{\mathrm{o}}, R_{\mathrm{w}}$, and measured resistivity $R_{\mathrm{t}}$, Eq. 2 can be used to calculate hydrate saturation $\left(S_{\mathrm{h}}\right)$. Gas hydrate saturation estimates from electrical resistivity $\operatorname{logs}$ are sensitive to $n$ at higher gas hydrate saturations. From a physical perspective, choosing a value for $n$ equal to that of $m$ implies the assumption that the effect of gas hydrate formation on the electrical resistivity is similar to that of simple effective porosity reduction. Pearson et al. (1983) calculated an estimate for $n$ of 1.94; however, modeling by Spangenberg (2001) has shown that $n$ depends somewhat on grain size distribution and the gas hydrate saturation itself. Gas hydrate saturation was estimated using $n=1.94, \mathrm{~m}=1.038$, and $\mathrm{a}=2.23$ from picket plot. The down-hole profiles of gas hydrate saturation $\left(S_{\mathrm{h}}\right)$ from resistivity at site NGHP-01-05 estimated using three different measurements of porosity are shown in Fig. 7b. All these yield similar results. Two zones in the interval from 70 to 79 and 81 to $93 \mathrm{~m}$ with predicted $S_{\mathrm{h}}$ values as high as $\sim 40 \%$ are observed assuming that gas hydrate fills the pore spaces of claybearing sediments (i.e., from isotropic modeling). Figure $7 \mathrm{~b}$ shows the anisotropic estimated gas hydrate saturation assuming that gas hydrate is present in fractures in clay-bearing sediments. Gas hydrates saturation in 

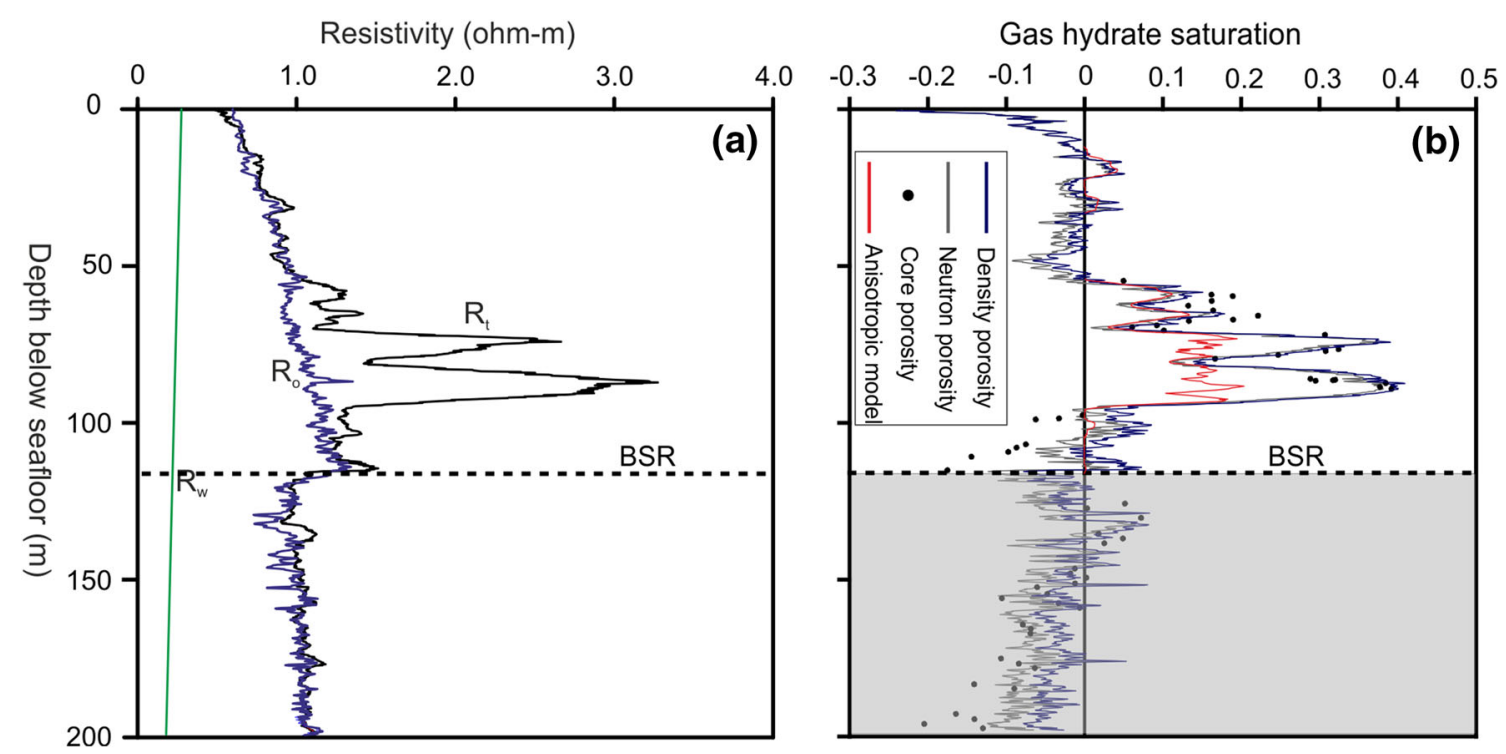

Fig. 7 a Measured logging-while-drilling (LWD) resistivity $R_{\mathrm{t}}$ (black) and $100 \%$ water-saturated resistivity $R_{\mathrm{O}}$ (blue), determined from the Archie's analysis of down-hole data at site NGHP-01-05, $R_{\mathrm{O}}$ calculated from the neutron porosity. Water-saturated sediment resistivity $R_{\mathrm{w}}$ (green) estimated from the in situ measurement at the site using Fofonoff (1985) equation of estate of seawater. b Gas

vertical fractures with variable actual dip angles. Anisotropic modeling result shows that the gas hydrates saturation value $\sim 20 \%$ of pore volume at study site. Comparing saturations estimated assuming isotropic Archie's equation with gas hydrate saturations estimated from the resistivity assuming a vertical fracture are reduced by a factor of about 2 .

Reflection seismic data inversion for various lithological and petrophysical attributes is generally used for reservoir characterization and detection of hydrocarbons. The model-based post-stack acoustic impedance technique was used in this study for gas hydrate identification and quantification. A post-stack inversion analysis was performed at the location of well NGHP-01-05 to evaluate the accuracy of the inversion and to calculate an amplitude scaling factor between the seismic data, and the impedance at the well. P-impedance was inverted from a single trace at the well location, then a synthetic trace was generated using this impedance, and the extracted P-wavelet was compared to the extracted trace from the real seismic trace at the well location (Fig. 8). The correlation coefficient between the synthetic (red) and the observed (black) seismograms is 0.79 at the well site. Within the more uniform shale interval, the inversion estimates are very close to the observed impedance. It is also important to remember that many of the hydrate-bearing intervals determined from cores are below the seismic vertical resolution, in which case the amplitudes of the seismic data could be hydrate saturation estimate from the resistivity log using Archie's analysis at site NGHP-01-05. Calculations are shown using three independent estimates of porosity: neutron $\log$, density porosity $\log$, and porosity measurements on cores. Red curve shows the gas hydrate saturation from anisotropic resistivity modeling

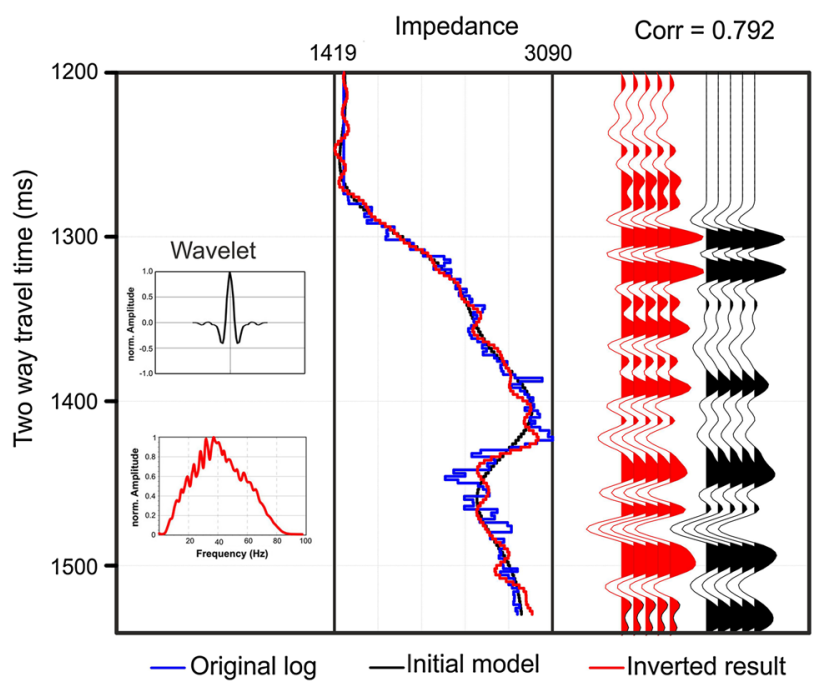

Fig. 8 Model-based post-stack inversion analysis at well NGHP-0105. P-impedance log (blue), initial P-impedance model (black), and inverted P-impedance (red). Synthetic trace generated from the inversion result (red) and extracted trace from the seismic volume (black) showing excellent matching. Extracted wavelet used for inversion with amplitude spectrum of the wavelet

significantly affected by tuning and interference effects from surrounding beds.

Following verification of the method at the well locations, the model-based inversion was performed on the seismic data using the extracted wavelet from the seismic 
Fig. 9 Initial model for modelbased acoustic impedance inversion of 2D multi-channel seismic data. Color code shows inverted P-impedance in $(\mathrm{m} / \mathrm{s}) \times(\mathrm{g} / \mathrm{cc})$
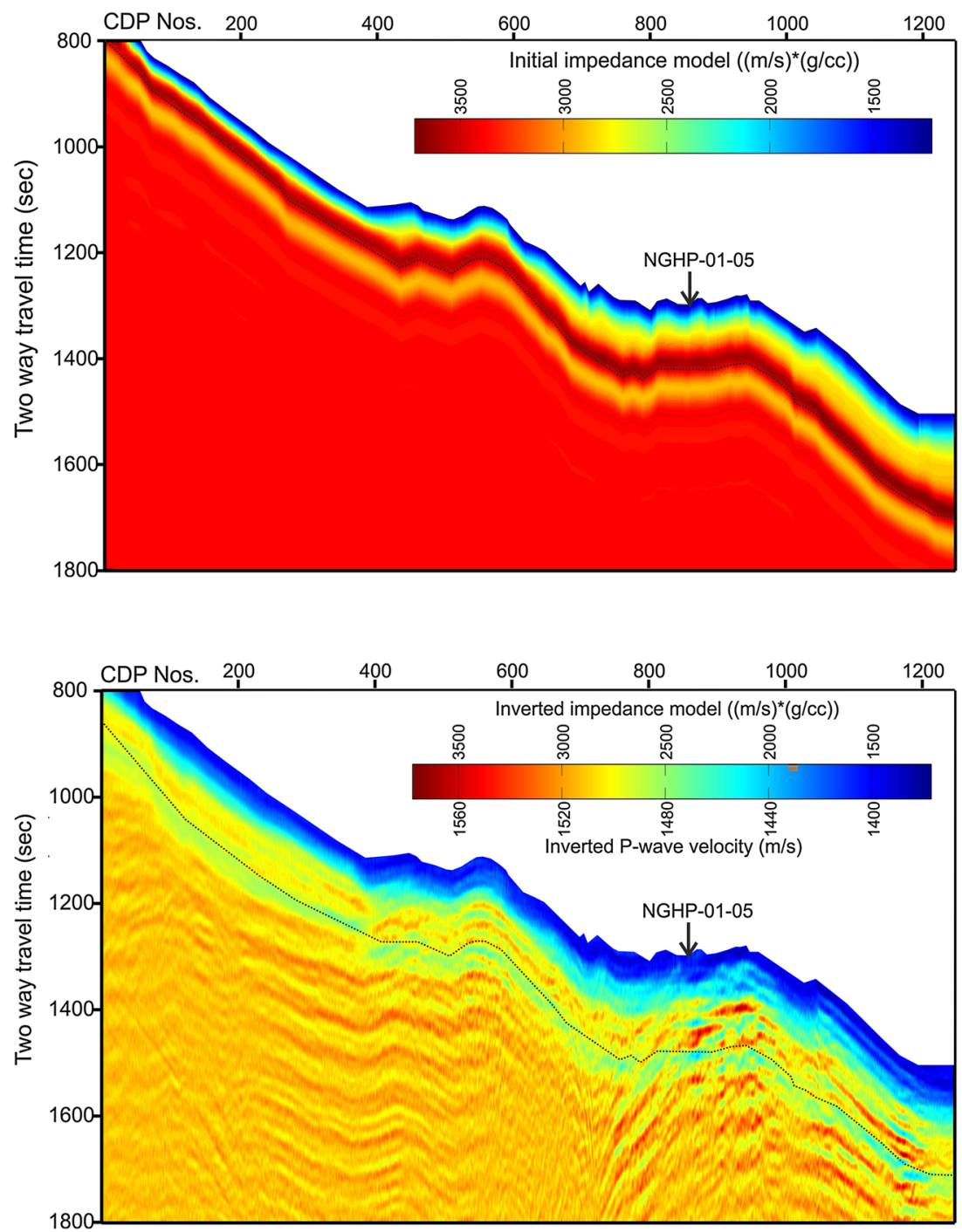

Fig. 10 Results from modelbased P-impedance inversion of the stacked volume along $2 \mathrm{D}$ seismic profile crossing well NGHP-01-05. Color code shows inverted P-impedance in $(\mathrm{m} / \mathrm{s}) \times(\mathrm{g} / \mathrm{cc})$
To estimate gas hydrate saturation velocity, porosity, and density parameters are required. Density was estimated simply by dividing inverted impedance by inverted velocity. Porosity was estimated from the density porosity relation $\varphi=\left(\rho_{\mathrm{g}}-\rho_{\mathrm{b}}\right) /\left(\rho_{\mathrm{g}}-\rho_{\mathrm{w}}\right)$. Where $\rho_{\mathrm{b}}$ is formation bulk density of the medium, $\rho_{\mathrm{w}}$ is density of pore water which is $1030 \mathrm{~kg} / \mathrm{m}^{3}$, and $\rho_{\mathrm{g}}$ is average grain density equal to $2750 \mathrm{~kg} / \mathrm{m}^{3}$ measured in the core moisture and density analysis. The porosity estimation using this method was tested at well $\log$ site NGHP-01-05 and extrapolated along the seismic profile. Inverted P-wave velocity converted to gas hydrate saturation is then achieved by applying the effective medium rock physics theory for a time/depth varying porosity-profile and assumed mineralogical mix (Shankar and Riedel 2011, 2013, 2014). Gas hydrate concentration from anisotropic P-wave velocity modeling along the NW-SE trending seismic profile is as high as $10-15 \%$ of the pore space (Fig. 11). Inset shows gas hydrate saturation at well log location from inverted 
Fig. 11 Estimated gas hydrate saturation along 2D seismic profile using effective medium rock physics model on inverted velocity from anisotropic $\mathrm{P}$-wave velocity modeling. Inset shows gas hydrate saturation at well $\log$ location from inverted velocity

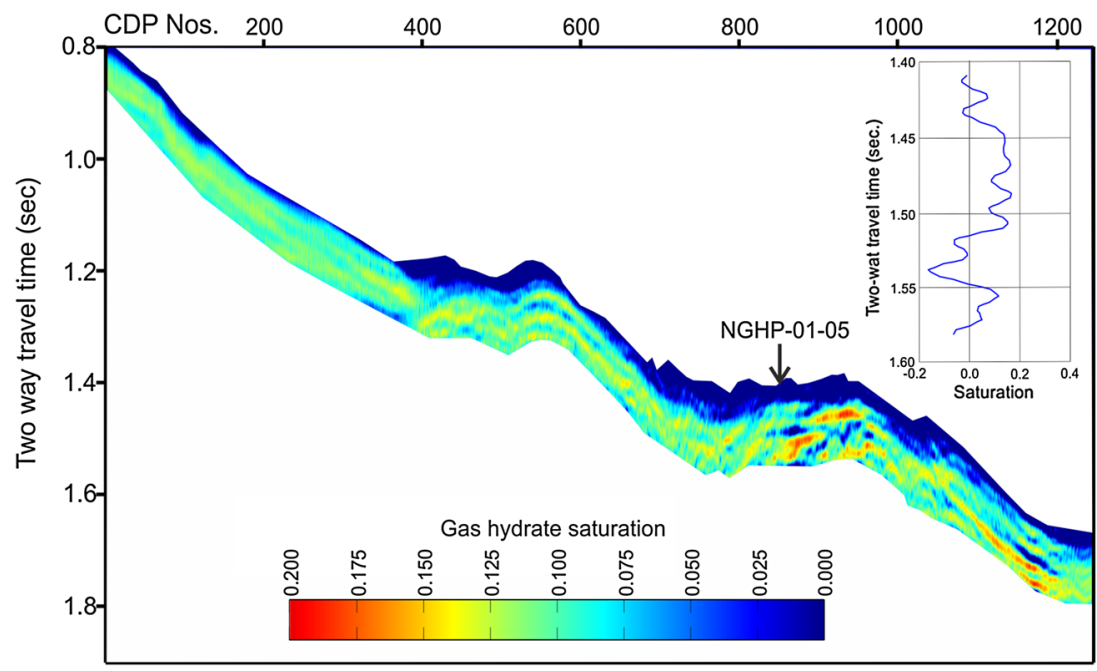

velocity in Fig. 11. Gas hydrate saturation follows acoustic impedance trend, i.e., higher acoustic impedance shows higher gas hydrate saturation above the base of gas hydrate stability zone (BGHSZ). High acoustic impedance just below the seafloor is observed in between CDP No. 800-1000 at around $1300 \mathrm{~ms}$ two-way travel time, indicating a gas hydrate-bearing zone (Fig. 10).

\section{Conclusions}

Post-stack acoustic impedance was calculated from the stacked seismic data using a post-stack model-based acoustic impedance inversion method constrained by well logs in the KG Basin. The model-based acoustic impedance inversion shows that low impedance at the BSR marks the base of the hydrate stability zone, confirmed by the well logs. Spatial distribution of gas hydrate saturation along $2 \mathrm{D}$ seismic profile from inverted velocity observed during acoustic impedance inversion varies maximum up to 10-15\% of the pore volume (Fig. 11). It was observed that the gas hydrate saturation increases towards deeper water depth in south-east direction and saturation decreases towards north-west direction shallow water depths from the drilling site. Maximum gas hydrate saturation was observed at the local gas hydrate reflector within gas hydrate stability zone where electrical resistivity logs also shows $\sim 20 \%$ gas hydrate saturation in few intervals from anisotropic modeling approach (Fig. 7b). This kind of saturation estimates provides spatial distribution of gas hydrate along seismic profile rather than at a log position, which can help to plan further logging and drilling expedition in this area and global gas hydrate saturation estimates.

Acknowledgments The author wishes to thank those that contributed to the success of the National Gas Hydrate Program
Expedition-01 (NGHP-01). NGHP-01 was planned and managed through collaboration between the Directorate General of Hydrocarbons (DGH) under the Ministry of Petroleum and Natural Gas (India), the U.S. Geological Survey (USGS), and the Consortium for Scientific Methane Hydrate Investigations (CSMHI) led by Overseas Drilling Limited (ODL) and FUGRO McClelland Marine Geosciences (FUGRO). The platform for the drilling operation was the research drill ship JOIDES Resolution, operated by ODL. Much of the drilling/coring equipment used was provided by the Integrated Ocean Drilling Program (IODP) through a loan agreement with the US National Science Foundation. Wireline pressure coring systems and supporting laboratories were provided by IODP/Texas A\&M University (TAMU), FUGRO, USGS, U.S. Department of Energy (USDOE) and HYACINTH/GeoTek. Downhole logging operational and technical support was provided by Lamont-Doherty Earth Observatory (LDEO) of Columbia University. The financial support for the NGHP-01, from the Oil Industry Development Board, Oil and Natural Gas Corporation Ltd., GAIL (India) Ltd. and Oil India Ltd. is gratefully acknowledged. We also acknowledge the support extended by all the participating organizations of the NGHP: MoP\&NG, DGH, ONGC, GAIL, OIL, NIO, NIOT, and RIL. U Shankar is grateful to the Indo-US Science and Technology Forum (IUSSTF), Government of India, New Delhi, for the Indo-US Fellowship-2013. Director, CSIR-NGRI, is acknowledged for the encouragement and constant support and Professor Anne M. Trehu for the valuable suggestions given during the preparation of the manuscript.

Open Access This article is distributed under the terms of the Creative Commons Attribution 4.0 International License (http:// creativecommons.org/licenses/by/4.0/), which permits unrestricted use, distribution, and reproduction in any medium, provided you give appropriate credit to the original author(s) and the source, provide a link to the Creative Commons license, and indicate if changes were made.

\section{References}

Archie E (1942) The electrical resistivity log as an aid in determining some reservoir characteristics. Trans Am Inst Min Metall Eng 146:54-62

Collett TS (2001) A review of well-log analysis techniques used to assess gas-hydrate-bearing reservoirs. In: Paull CK, Dillon WP (eds) Natural gas hydrates: occurrence, distribution, and 
detection, vol 124., Geophysical monographsAmerican Geophysical Union, Washington, pp 189-210

Collett TS, Godbole SP, Economides CE (1984) Quantification of in situ gas hydrates with well logs. Proc Ann Technol Meet Pet Soc 35:571-582

Collett TS, Lewis RE, Dallimore SR, Lee MW, Mroz TH, Uchida T (1999) Detailed evaluation of gas hydrate reservoir properties using JAPEX/JNOC/GSC Mallik 2L-38 gas hydrate research well downhole well-log displays. Geol Survey Can Bull 544:295-311

Collett TS, Riedel M, Cochran JR, Boswell R, Presley J, Kumar P, Sathe AV, Sethi A, Lall M, Sibal V, NGHP Expedition 01 Scientists (2008) National Gas Hydrate Program Expedition 01 initial reports: Directorate General of Hydrocarbons, New Delhi

Cook AE, Goldberg D (2008) Extent of gas hydrate filled fracture planes: implications for in situ methanogenesis and resource potential. Geophys Res Lett 35:L15302. doi:10.1029/ 2008GL034587

Cook AE, Goldberg D, Malinverno A (2014) Natural gas hydrates occupying fractures: a focus on non-vent sites on the Indian continental margin and the northern Gulf of Mexico. Mar Pet Geol 58:278-291

Dai J, Xu HB, Snyder F, Dutta N (2004) Detection and estimation of gas hydrates using rock physics and seismic inversion: examples from the northern deepwater Gulf of Mexico. Lead Edge 23(1):60-66

Dai J, Snyder F, Gillespie D, Koesoemadinata A, Dutta N (2008) Exploration for gas hydrates in the deep water, northern Gulf of Mexico: Part I, A seismic approach based on geologic model, inversion, and rock physics principles. Mar Pet Geol 25:830-844

Dickens GR, O'Neil JR, Rea DK, Owen RM (1995) Dissociation of oceanic methane hydrate as a cause of the carbon isotope excursion at the end of the Paleocene. Paleoceanography 10:965-971

Dvorkin J, Nur A (1993) Rock physics for characterization of gas hydrates. In: Howell DG (ed), The future of energy gases, U.S. Geological Survey Professional Paper, 1570, pp 293-311

Fofonoff NP (1985) Physical properties of seawater: a new salinity scale and equation of state for seawater. J Geophys Res 90(C2):3332-3342

Guerin G, Goldberg D, Melsterl A (1999) Characterization of in situ elastic properties of gas hydrate-bearing sediments on the Blake Ridge. J Geophys Res 104:17781-17796

Helgerud MB, Dvorkin J, Nur A (1999) Elastic-wave velocity in marine sediments with gas hydrates: effective medium modeling. Geophys Res Lett 26(13):2021-2024

Hilfer R (1991) Geometric and dielectric characterization of porous media. Phys Rev B Condens Matter 44(1):60-75

Hyndman RD, Moore GF, Moran K (1993) Velocity, porosity, and pore-fluid loss from the Nankai subduction zone accretionary prism. Proc ODP Sci Results 131:211-220

Hyndman RD, Yuan T, Moran K (1999) The concentration of deep sea gas hydrates from downhole electrical resistivity logs and laboratory data. Earth Planet Sci Lett 172(1-2):167-177

Ioannidis MA, Kwiecien MJ, Chatzis I (1997) Electrical conductivity and percolation aspects of statistically homogeneous porous media. Transp Porous Media 29(1):61-83

Jackson PD, Taylor SD, Stanford PN (1978) Resistivity-porosityparticle shape relationships for marine sands. Geophysics 43(6): 1250-1268

Kennedy WD, Herrick DC (2004) Conductivity anisotropy in shalefree sandstone. Petrophysics 45:38-58

Kleinberg RL, Flaum C, Straley C, Brewer PG, Malby GE, Peltzer ET, Friederich G, Yesinowski JP (2003) Seafloor nuclear magnetic resonance assay of methane hydrate in sediment and rock. J Geophys Res 108:2137. doi:10.1029/2001JB000919
Kvenvolden KA (1993) Gas hydrates-geological perspective and global change. Rev Geophys 31:173-187

Lee MW (2009) Anisotropic velocities of gas hydrate-bearing sediments in fractured reservoirs, U.S. Geological Survey Scientific Investigations Report 2009-5141, p 13

Lee MW, Collett TS (2008) Integrated analysis of well logs and seismic data at the Keathley Canyon, Gulf of Mexico, for estimation of gas hydrate concentrations. Mar Pet Geol 25:924-931

Lee MW, Collett TS (2009) Gas hydrate saturations estimated from fractured reservoir at Site NGHP-01-10, Krishna-Godavari Basin, India. J Geophys Res 114:B07102. doi:10.1029/ 2008JB006237

Lee MW, Collett TS (2012) Pore- and fracture-filling gas hydrate reservoirs in the Gulf of Mexico Gas Hydrate Joint Industry Project Leg II Green Canyon 955 H wel. Mar Pet Geol 34:62-71

Lee MW, Hutchinson DR, Dillon WP, Miller JJ, Agena WF, Swift BA (1993) Method of estimating the amount of in situ gas hydrates in deep marine sediments. Mar Pet Geol 10:496-506

Lindseth RO (1979) Synthetic sonic logs-a process for stratigraphic interpretation. Geophysics 44:3-26

Lu S, McMechan GA (2002) Estimation of gas hydrate and free gas saturation, concentration, and distribution from seismic data. Geophysics 67:582-593

Mathews M (1986) Logging characteristics of methane hydrate. Log Anal 27(3):26-63

Milkov AV (2004) Global estimates of hydrate-bound gas in marine sediments: How much is really out there? Earth-Sci Rev 66:183-197

Nixon MF, Grozic JLH (2007) Submarine slope failure due to gas hydrate dissociation: a preliminary quantification. Can Geotech J 44(3):314-325

Paull CK, Ussler W, Dillon WP (2000) Potential role of gas hydrate decomposition in generating submarine slope failures. In: Max MD (ed) Natural gas hydrate in oceanic and permafrost environments. Kluwer Academic Publishers, Dordrecht, pp 149-156

Pearson CF, Halleck PM, McGuire PL, Hermes R, Mathews M (1983) Natural gas hydrate: a review of in situ properties. J Phys Chem $87: 4180-4185$

Pendrel J (2001) Seismic inversion-the best tool for reservoir characterization. CSEG Rec 26(1):18-24

Pinero E, Marquardt M, Hensen C, Haeckel M, Wallmann K (2013) Estimation of the global inventory of methane hydrates in marine sediments using transfer functions. Biogeosciences 10:959-975

Ramana MV, Ramprasad T, Paropkari AL, Borole DV, Rao BR, Karisiddaiah SM, Desa M, Kocherla M, Joao HM, Lokabharati P, Gonsalves MJ, Pattan JN, Khadge NH, Babu CP, Sathe AV, Kumar P, Sethi AK (2009) Multidisciplinary investigations exploring indicators of gas hydrate occurrence in the KrishnaGodavari Basin offshore, east coast of India. Geo-Mar Lett 29:25-38

Rao GN (2001) Sedimentation, stratigraphy, and petroleum potential of Krishna-Godavari basin, east coast of India. Am Assoc Pet Geol Bull 85(9):1623-1643

Riedel M, Shankar U (2012) Combining impedance inversion and seismic similarity for robust gas hydrate concentration assessments-a case study from the Krishna-Godavari basin, East Coast of India. Mar Pet Geol 36:35-49

Riedel M, Collett TS, Shankar U (2011) Documenting channel features associated with gas hydrates in the Krishna-Godavari Basin, offshore India. Mar Geol 279:1-11

Russell B, Hampson D (1991) Comparison of post stack inversion methods: 61st Annual international meeting, SEG, expanded abstracts, 10: 876-878 
Shankar U, Riedel M (2010) Seismic and heat flow constraints from the Krishna-Godavari Basin gas hydrate system. Mar Geol 276:1-13

Shankar U, Riedel M (2011) Gas hydrate saturation in the KrishnaGodavari basin from P-wave velocity and electrical resistivity logs. Mar Pet Geol 28:1768-1778

Shankar U, Riedel M (2013) Heat flow and gas hydrate saturation estimates from Andaman Sea, India. Mar Pet Geol 43:434-449

Shankar U, Riedel M (2014) Assessment of gas hydrate saturation in marine sediments from resistivity and compressional-wave velocity log measurements in the Mahanadi Basin, India. Mar Pet Geol 58:265-277

Spangenberg E (2001) Modeling of the influence of gas hydrate content on the electrical properties of porous sediments. J Geophys Res 106(B4):6535-6548

Swanson BF (1979) Visualizing pores and non-wetting phase in porous rock. J Pet Technol 31(1):10-18

Wallmann K, Pinero E, Burwicz E, Haeckel M, Hensen C, Dale A, Ruepke L (2012) The global inventory of methane hydrate in marine sediments: a theoretical approach. Energies 5:2449-2498

Wang XJ, Hutchinson DR, Wu SG, Yang SX, Guo YQ (2011) Elevated gas hydrate saturations within silt and silty-clay sediments in the Shenhu area, South China Sea. J Geophys Res 116:1-18. doi:10.1029/2010JB007944

White JE (1965) Seismic waves-radiation, transmission, and attenuation. McGraw-Hill, New York, p 302

Wood AB (1941) A text book of sound. MacMillan Publishing, New York, p 578

Wyllie MRJ, Gregory AR, Gardner GHF (1958) An experimental investigation of factors affecting elastic wave velocities in porous media. Geophysics 23:459-493

Yuan T, Hyndman RD, Spence GD, Desmons B (1996) Seismic velocity increase and deep-sea gas hydrate above a bottomsimulating reflector on the northern Cascadia continental slope. J Geophys Res 101:13655-13671 